\title{
Noción de víctima y conflicto armado en Colombia: hermenéutica, ciudadania y equidad de género
}

\section{The notion of victim and the Colombian armed conflict: hermeneutics, citizenship and gender equity}

\section{Ledis Bohórquez Farfán (i)}

Universidad Pontificia Bolivariana

ledis.bohorquez@upb.edu.co

\section{Priscyll Anctil Avoine (iD}

Université du Québec à Montréal

anctil avoine.priscyll@courrier.uqam.ca

\section{Yuber Hernando Rojas Ariza (iD)}

Universidad Pontificia Bolivariana

yuber.rojas@upb.edu.co

\section{Resumen}

El presente artículo tiene como objetivo analizar, desde tres ejes, los límites del concepto de víctima implícitos en la Ley de Víctimas y Restitución de Tierras (Ley 1448 de 2011). Estos tres ejes se presentan así: en primer lugar, el análisis sobre el concepto de víctima a partir de la filosofia politica y su relación con la violencia en perspectiva hermenéutica; en segundo lugar, la profundización en la noción de víctima desde el ejercicio real de ciudadanía; $y$, en tercer lugar, la interpretación de las limitaciones de la noción de víctima desde la equidad de género. El resultado: existe un concepto de víctima excluyente e inoperativo, que promueve la segregación y limita, tanto el ejercicio real de ciudadanía como las posibilidades de avanzar en la equidad de género. En síntesis: una noción de víctima que profundiza las relaciones de poder y recrea ciertos tipos de violencias resultantes del conflicto armado colombiano.

Palabras clave: Víctimas; Violencia; Hermenéutica; Ciudadanía; Equidad de género.

\begin{abstract}
The purpose of this article is to analyze, from three points of view, the limits of the concept of victim, implicit in Law 1448 of 2011, known as the Victims and Land Restitution Law. These three axes are presented as such: first, drawing upon political philosophy, an analysis of the concept of victim and its relation to violence from a hermeneutic perspective; second, the deepening of the notion of victim from the exercise of citizenship; and third, the interpretation of the limitations of the notion of victim from a gender equity perspective. The result: there is an exclusionary and inoperative concept of victim,
\end{abstract}


which promotes segregation and limits both the real exercise of citizenship and the possibilities of advancing gender equity in Colombia. To sum up, a notion of victim that deepens power relations and recreates certain types of violence resulting from the Colombian armed conflict.

Keywords: Victims; Violence; Hermeneutics; Citizenship; Gender Equity.

Articulo: Recibido el 12 de diciembre de 2018 y aprobado el 12 de julio de 2019.

\section{Cómo citar este artículo :}

Bohórquez Farfán, L., Anctil Avoine, P., Rojas-Ariza, Y. (2019). Noción de víctima y conflicto armado en Colombia: hermenéutica, ciudadanía y equidad de género. Reflexión Política 21(42), pp. 30-42. doi: 10.29375/01240781.3469

\section{Introducción}

La noción de víctima está tanto en el corazón de la historia contemporánea de Colombia como en el impacto social incalculable de la guerra que ha padecido este país. Las cifras indican que los distintos actores armados, legales e ilegales son responsables del daño causado a 8.847.047 víctimas, según el Registro Único de Víctimas (RUV) (2019). Y justamente, ese carácter civil de la guerra ha cobrado la vida de miles de colombianos y colombianas durante décadas. Sin embargo, la historia ha sido escrita por los vencedores y no por los vencidos. O para hacer más explícita la aseveración: una historia que no le ha dado voz a los civiles "vencidos", es decir, a las víctimas del conflicto armado colombiano. Un país donde han reinado el silencio, el olvido y la impunidad.

La actual implementación del proceso de paz entre la guerrilla de las Fuerzas Armadas Revolucionarias de Colombia - Ejército del Pueblo (FARC-EP) y el gobierno colombiano ha dado otro rumbo, en término práctico y analítico, al concepto de víctima. En efecto, se ha puesto un énfasis especial en la participación de los colectivos de víctimas, pero también, se ha querido de-construir la dicotomía entre persona víctima y persona victimaria. Este contexto, y el valor dado a la noción de víctima en el marco del acuerdo de paz firmado en 2016, ha sido posible por el continuo activismo de los grupos y colectivos de víctimas, así como a partir de la implementación de la Ley 1448 de 2011, conocida Ley de Víctimas y Restitución de Tierras (República de Colombia, 2011). Dicha ley ha sido un importante avance en materia de reconocimiento de las víctimas: ha posibilitado espacios de reconstrucción de la memoria de las víctimas del conflicto y ha dado lugar al reconocimiento jurídico de esta condición como herramienta contra el olvido. A pesar de esto, los obstáculos alrededor de su implementación han dificultado la superación de la "condición" de víctima, especialmente desde el punto de vista político, para transformar las estructuras de opresión y violencia que persisten. Cabe preguntarse entonces, ¿existen otras posibilidades para pensar la apertura del concepto de víctima más allá de lo jurídico?

Este artículo presenta los resultados de una investigación titulada Los límites del concepto de víctima: Un estudio desde el ejercicio de ciudadanía y equidad de género en Colombia, conducida por el Grupo Interdisciplinario de Estudios sobre Cultura, Derechos Humanos y Muerte de la Universidad Pontificia Bolivariana - Seccional Bucaramanga. Tiene como objetivo analizar, desde tres ejes, los límites del concepto de víctima implícitos en la Ley 1448 de 2011, conocida como Ley de Víctimas y Restitución de Tierras. Estos tres ejes se presentan de la siguiente forma: en primer lugar, el análisis sobre el concepto de víctima a partir de la filosofía política y su relación con la violencia en perspectiva hermenéutica; en segundo lugar, la profundización en la noción de víctima desde el ejercicio real de ciudadanía; y en tercer lugar, la interpretación de las limitaciones de la noción de víctima desde la equidad de género.

En ese contexto, la investigación emprendida acerca de los límites del concepto de víctima resulta 
importante porque permite una mirada crítica y, por ende, posibilita abrir la noción de víctima. El objetivo, entonces, es mostrar desde esa perspectiva crítica los límites del concepto de víctima de la Ley 1448 del 2011, y abrir el concepto de víctimas a otras posibilidades e interpretaciones.

\section{La noción de víctima en medio del conflicto armado: una aproximación hermenéutica}

El análisis hermenéutico del concepto de víctima es fundamental para una re-interpretación de las múltiples violencias en el marco del conflicto armado en Colombia. Sin caer en un anacronismo conceptual, en este apartado queremos abrir las posibilidades de interpretación sobre el concepto con el fin de poder hallar su multiplicidad. Por consiguiente, se trata de plantear la pregunta que posibilite superar el efecto adverso: la univocidad conceptual. En esa perspectiva, la pregunta es la siguiente: ¿Qué significa ser víctima en el marco de la guerra?

Para poder abordar esta cuestión se requiere establecer su presunta génesis y desarrollo, cuyo proceso permitirá una mirada más amplia sobre el caso colombiano. Cabe mencionar que no se trata de un exhaustivo análisis históricocomparativo entre Alemania y Colombia, sino una re-interpretación que permita abrir horizontes de análisis y la superación de la univocidad (y del reduccionismo) conceptual.

\section{Rompiendo su univocidad: algunos elementos para su comprensión}

$\mathrm{El}$ concepto de víctima adquiere especial relevancia en la época de posguerra a mediados del siglo XX y está ligado a la construcción de la memoria histórica a partir de los millones de muertos que dejó la Segunda Guerra Mundial. Se caracteriza por tener un componente jurídico en términos de presuponer a un victimario claro y definido pese a que la concepción de víctima, a falta de narrativas que permitieran versiones desde dicha óptica, difícilmente puede tener un matiz claro y definido. En consecuencia, la complejidad de la relación víctima-victimario trastoca los límites en los cuales se establece una "zona gris”, tal y como lo analiza Primo Levi en la Trilogía de Auschwitz (2015, pp. 497-528).

Para el caso concreto de la Segunda Guerra Mundial, el régimen nazi se convirtió en victimario y los sometidos y asesinados bajo su poder se transformaron en la figura de victima. La posterior captura de los responsables de la barbarie del régimen nazi y su proceso de juzgamiento - por ejemplo, los juicios de Nuremberg (1945-46) llamó la atención de la filósofa alemana Hannah Arendt cuya interpretación crítica quedó plasmada en su obra Eichmann en Jerusalén y develó la banalidad del mal a partir de su análisis sobre el juicio de Eichmann, realizado en 1961. De manera similar a la experiencia de Arendt como exiliada (y sobreviviente), también lo manifestó Primo Levi, quien vivió el horror de los campos de concentración; ambos sobrevivientes de la Segunda Guerra Mundial y víctimas del régimen nazi, que lograron una narrativa de cara a la memoria histórica de los caídos.

No obstante, del ámbito de la guerra se pasa al lenguaje jurídico-político, cuya transición encasilla al "sobreviviente". Pasó con los victimarios del régimen nazi juzgados en la posguerra, que fue objeto de interpretación filosófica de Arendt y Levi, y también pasa con el lenguaje que se instaura desde la década de los sesenta en el mundo: el concepto de víctima deja de lado la noción de sobreviviente de la guerra. Por ejemplo, en Colombia el llamado Frente Nacional (1958-1970) no habla ni siquiera de víctima sino de damnificado por la violencia (Jaramillo, 2014), lo cual significó entender que el sujeto que padece la guerra, simplemente se observaba como un daño colateral frente a la prioridad en atención que tuvieron los gobiernos de turno de cara a los daños materiales ocasionados: “(...) estaban más preocupados por las zonas de violencia que por los sujetos victimizados" (Jaramillo, 2014, p.85). Solamente hasta la década de los ochenta la noción de víctima se reconoce en el plano del orden jurídico (internacional) más allá de la derivación del lenguaje de posguerra: se amplía su concepción. En la Declaración de las Naciones Unidas sobre principios fundamentales de Justicia se hace explícitamente alusión a la concepción de víctima:

[...] las personas que, individual o colectivamente, hayan sufrido daños, inclusive lesiones físicas o mentales, sufrimiento emocional, pérdida financiera o menoscabo sustancial de sus derechos fundamentales, como consecuencia de acciones $\mathrm{u}$ omisiones que violen la legislación penal vigente en los Estados Miembros, incluida la que proscribe el abuso de poder. Para las víctimas de delitos y del abuso de poder. (Naciones Unidas, 1985, p. 313). 
Sin embargo, mientras esto acontecía en el plano internacional, en Colombia comenzaba el genocidio contra la Unión Patriótica que, para hacer precisión, entre 1984 y 2002 dejó más de 4.153 integrantes asesinados y/o desaparecidos, según el Observatorio de Memoria y Conflicto del Centro Nacional de Memoria Histórica (CNMH). Lejos de acoger la directriz de las Naciones Unidas, las décadas de los ochenta y noventa se convirtieron en un período de profundización de la guerra donde desaparece la víctima como sujeto, y en su lugar, continúa el tratamiento de damnificado por la violencia de la década de los sesenta. $\mathrm{El}$ discurso de víctima del conflicto armado queda entonces ligado en un principio a la categoría de damnificado de la violencia y pasa a llamarse desplazado por la violencia: en la vida práctica y uso común del lenguaje, se habla de víctima y desplazado como sinónimos. No obstante, pierde curiosamente la arista de sobreviviente desde el eco del discurso estatal que se extiende por la sociedad y el mundo entero.

Así, bajo ese eufemismo que recubrió el fin de siglo $\mathrm{XX}$ en Colombia donde se mostraba al desplazado como el único sujeto que padecía la guerra en Colombia, nació la categoría de Víctima en la primera década del siglo XXI. Se comienza a configurar la noción de víctima como concepto que se corresponde con la situación de violencia que se ha padecido en el país. En ese contexto, por ejemplo, nace en 2005 el Movimiento de Víctimas de Crímenes de Estado (MOVICE), organización de base social que no solamente logró congregar a distintas organizaciones defensoras de derechos humanos del país (MOVICE, 2015), sino que además se convirtió en la respuesta (y resistencia) frente al Estado colombiano y el gobierno de Álvaro Uribe Vélez (20022010), el cual trató a las víctimas y defensores de DDHH como "auxiliadores del terrorismo", mientras dicho gobierno realizaba el Acuerdo de paz con los paramilitares, denominado como Justicia y Paz. En consecuencia, se puede afirmar que la noción de víctima se robustece y adquiere vida propia gracias a la lucha y organización social en medio de la guerra, seis años antes de formalizarse por parte del Estado en la Ley 1448 de 2011 (o Ley de Víctimas y Restitución de Tierras), que más adelante trataremos en detalle desde el ejercicio de la ciudadanía y la equidad de género.

En resumidas cuentas: sea la concepción de damnificado de la violencia que reinó desde los sesenta hasta los noventa, o desplazado de la violencia como lenguaje de los noventa y la primera década del siglo XXI, o inclusive como víctima de la violencia a partir de la Ley 1448 de 2011, lo cierto es que desaparece el sujeto constructor de memoria histórica: los sobrevivientes. En medio de esta transformación de la noción de víctima, vale la pena resaltar nuevamente la pregunta: ¿qué significa ser víctima del conflicto armado? Frente a esta pregunta, se hace necesario hacer una re-interpretación acerca de la violencia en Colombia que permita el papel protagónico de las llamadas víctimas del conflicto armado desde elementos filosóficos.

\section{Victima (s) de la violencia: hacia una apertura del concepto}

Es importante decir que, generalmente, la literatura sobre la violencia ha versado sobre el periodo de violencia (mediados del siglo XX). La lectura más robusta y los aportes más significativos se han hecho desde los estudios históricos como los realizados por Gonzalo Sánchez en su libro Bandoleros, gamonales y campesinos: el caso de la violencia en Colombia (1983) o aquellos que se publicaron mientras estuvo al frente del Centro Nacional de Memoria Histórica (CNMH) durante el 2011 y 2018. También cabe resaltar el denominado grupo de violentólogos, académicos especialistas en los procesos de violencia en Colombia, que sentaron bases para estudios históricos, políticos e inclusive culturales. Algunas de sus figuras más representativas son los investigadores Gonzalo Sánchez, Álvaro Camacho Guizado, Eduardo Pizarro Leongómez, Francisco Leal Buitrago y, con notoria agudeza, María Victoria Uribe Alarcón con sus investigaciones sobre antropología de la violencia; de igual forma se destaca el trabajo del Grupo de Memoria Histórica (2007-2011) y el Instituto de Estudios Políticos y Relaciones Internacionales (IEPRI). Por otra parte, también está quizá la obra más emblemática escrita recientemente: Contribución al entendimiento del conflicto armado en Colombia (2015), en la cual se recogen 14 ensayos y se hace una formidable sintesis del proceso de violencia colombiano.

Si bien son grandes aportes para la comprensión del conflicto armado en Colombia, queremos resaltar que falta apuntalar una reflexión teórica sobre el concepto de víctima en el marco del proceso de violencia en Colombia. Esa deuda de la investigación - y de la academia colombiana - debe 
subsanarse con estudios teóricos que den paso a la posibilidad de lograr una teoría interpretativa (fundamentalmente filosófica) que rinda cuentas sobre nuestra convulsionada historia reciente y su modus operandi. Desde la filosofía política en comunión con la hermenéutica se puede dar paso a una hermenéutica de la violencia que proporcione la comprensión de la misma y su superación. En efecto, los aportes de Hannah Arendt (2006), al igual que la lectura de Primo Levi (2015) y Byung Chul Han (2016) posibilitan ese Topos o espacio de pensamiento.

El concepto de víctima aquí resaltado desde la perspectiva hermenéutica en clave de filosofía política, más allá de lo novedoso del abordaje, sugiere que se ha entendido como una relación violencia-víctima fenomenológicamente. Dicha interpretación de la violencia como fenómeno, la ha situado y supeditado al plano político, económico, social y cultural. Esa interpretación clásica de violencia en relación con la concepción de víctima, no permite entender que la relación violenciavíctima es fundamentalmente cambiante, dinámica e inclusive autónoma. En otras palabras, el debate radica en una re-interpretación de violencia-víctima como categoría analítica que permite entender el modo-de-ser del colombiano en su proceso de devenir constante, sin que ello sea una pretensión de universalidad. En resumen: pareciera que la relación violencia-víctima se forma, reforma y transforma hasta el punto de convertirse en piedra angular y explicativa del devenir histórico de Colombia.

Ahora bien, si la discusión acerca de la relación violencia-víctima es controversial en tanto que se cambia el espacio desde el cual se interpreta, no menos controversial es la relación víctima-victimario o victimaria. Tal relación se convierte en el fundamento del plano político, más allá de la audaz interpretación clásica de Carl Schmitt (amigo-enemigo) en su libro El concepto de lo político (2016). En efecto, el resultado analítico que aquí se sostiene indica que no solamente el conflicto armado (colombiano) se explica por la relación víctima-victimario/a sino también por el plano político y su praxis jurídica. Eso significa que la relación víctima-victimario/a se convierte en el sostén del funcionamiento jurídico (Sampedro Arrubla, 1998) pero también en un diferencial importante desde la psicología social (Ballesteros, López y Pearson, 2008).

Además de las dos relaciones expuestas (violencia-víctima y víctima-victimario/a), la discusión recae sobre el carácter topológico de la violencia. Mientras el filósofo surcoreano Byung Chul Han sostiene una macrofísica y microfísica de la violencia (Han, 2016), nuestro estudio sostiene que la línea divisoria entre lo uno y lo otro es un nuevo Topos en el cual se localiza una especie de mesofisica de la violencia que adquiere autonomía porque no es ni macro ni microfísica; más bien se trata de una violencia que se trastoca por el lenguaje y es tan violenta como sutil tanto hacia "dentro" como hacia "afuera" del yo: una especie de cuerpo de la violencia (Rojas, 2017, p. 753).

Eso significa que, en esa zona gris donde emerge una especie de mesofisica de la violencia, se encuentra el pilar para la teorización de la violencia en Colombia y su relación con las víctimas. Ese vacío de la academia con respecto a la violencia desde un abordaje filosófico, posiblemente ha legitimado las mismas prácticas violentas en tanto que, a falta de acción, se ha actuado por omisión. Una omisión intelectual en el mismo seno del sistema educativo que deja en una situación desfavorable a la praxis filosófica en particular, y a las ciencias sociales y humanidades en general. El reto ahora consiste en el desmonte discursivo del concepto de víctima y la necesaria re-interpretación sobre la violencia.

Es precisamente en la apertura del concepto de víctima donde emerge el plural "víctimas" y es posible abordar de forma crítica la Ley 1448 de 2011, así como revelar su funcionamiento: el proceso de cosificación de lo humano. De manera que la discusión sugerida busca romper con la univocidad del concepto de víctima y habla más bien de su multiplicidad. Pero, ¿cómo comprender la concepción de víctima más allá de su univocidad? ¿Cómo comprender la praxis de la multiplicidad de las víctimas a partir del ejercicio real de la ciudadanía y la equidad de género?

\section{Hacia nuevos horizontes: posibilidades ciudadanas}

El concepto de ciudadanía es milenario: se puede rastrear desde la filosofía griega hasta nuestros días, con énfasis distintos en cada época y dependiendo del enfoque de su abordaje. De esta manera, diversos autores y autoras han hablado del tema, con énfasis particulares y en momentos distintos, dentro de los cuales vale mencionar a Thomas Marshall (1950), Adela Cortina (1997), Esteban Antxustegui (2010), Juan Antonio Horrach (2009), Arthur Benz (2010), 
Jhon Rawls (2002), Jürgen Habermas (1999) y Will Kymlicka (1996). Sus aportes han permitido comprender que el concepto de ciudadanía hace referencia al estatus que poseen las personas en el marco de la comunidad política, sujeto a normas y en relación con otros dentro de un territorio. Por ello, existen dos elementos constitutivos del concepto: el Estado y la sociedad, dentro de la cual se cuentan los movimientos sociales y grupos de presión, entre otros. "La ciudadanía es aquel estatus que se concede a los miembros de pleno derecho de una comunidad. Sus beneficiarios son iguales en cuanto a los derechos y las obligaciones que implica” (Marshall y Bottomore, 1950, p. 37).

Para Cortina, el concepto en sí mismo involucra una dimensión jurídica relacionada con los derechos, una dimensión moral que implica obligaciones, y una dimensión espacial y relacional en términos de la pertenencia a una comunidad: “[...] un concepto pleno de ciudadanía integra un status legal (un conjunto de derechos), un status moral (un conjunto de responsabilidades) y también una identidad, por la que una persona se sabe y siente perteneciente a una sociedad" (Cortina, 1997, p. 77).

Las dinámicas cambiantes de cada momento histórico han lidiado problemas que han conllevado a un abordaje más amplio de la ciudadanía, que lejos está ya de circunscribirse solamente a la ciudadanía civil y política de los inicios. De hecho, muchas teóricas y teóricos en filosofía política han hecho críticas al modelo de ciudadanía tal como se ha pensado a partir de la Revolución francesa; Wollestonecraft (1996) y De Gouges (1791) son dos ejemplos de mujeres que han denunciado el marco de ciudadanía pensado desde un sujeto masculino y exclusivo. Así, desde su propia evolución histórica, el concepto de ciudadanía ha excluido poblaciones con base en una visión esencialista del sujeto que la podía ejercer. Como lo ha apuntado Pateman (2010), el famoso contrato social de Locke, el cual marca las pautas de la apariencia en lo público, siempre ha ocultado un "contrato sexual", excluyendo las mujeres del ámbito político.

De este modo, la modernidad política en Europa fue la época en la que se gestaron los modelos de ciudadanía, los cuales todavía marcan las instituciones y formas diversas de hacer política en la actualidad. Es así que el estudio de Bohórquez (2016) recopila diversas líneas o tipos de ciudadanía, conservando la civil y la política, tales como la ciudadanía social (introducida por Thomas Marshall), la ciudadanía liberal, republicana, comunitaria, libertaria, económica, intercultural, diferenciada y multicultural, de las que se halló registros.

Para la investigación que se está llevando a cabo, en la que se trabaja en la comprensión y profundización del ejercicio real de ciudadanía de este sector de población, la base del análisis es la ciudadanía política, que comporta la participación política como eje fundamental. Para ello valga traer a colación la definición de participación de Fandiño, citado por Nader:

Por participación en forma general se entiende la actividad ciudadana de carácter individual o colectiva dirigida a expresar y defender sus intereses, tomar parte en la administración de los asuntos comunes y en los centros de poder, tanto en la toma de decisiones como en el control de la acción gubernamental (2008, p. 282).

En la lógica expuesta, para analizar los niveles de participación ciudadana de la población víctima del conflicto armado colombiano, se hace necesario partir del concepto de víctima, estipulado en la Ley 1448, y que se expresa como sigue:

Se consideran víctimas, para los efectos de esta ley, aquellas personas que individual o colectivamente hayan sufrido un daño por hechos ocurridos a partir del $1^{\circ}$ de enero de 1985 , como consecuencia de infracciones al Derecho Internacional Humanitario o de violaciones graves y manifiestas a las normas internacionales de Derechos Humanos, ocurridas con ocasión del conflicto armado interno.

También son víctimas el cónyuge, compañero o compañera permanente, parejas del mismo sexo y familiar en primer grado de consanguinidad, primero civil de la víctima directa, cuando a esta se le hubiere dado muerte o estuviere desaparecida. A falta de estas, lo serán los que se encuentren en el segundo grado de consanguinidad ascendente.

De la misma forma, se consideran víctimas las personas que hayan sufrido un daño al intervenir para asistir a la víctima en peligro o para prevenir la victimización (República de Colombia, 2011, Artículo 3ํํ).

La participación de las víctimas está definida en la Ley 1448 de 2011 en el Artículo 192: "Es deber del Estado garantizar la participación 
efectiva de las víctimas en el diseño, implementación ejecución y seguimiento al cumplimiento de la Ley y los planes, proyectos y programas que se creen con ocasión de la misma" (República de Colombia, 2011, Artículo 192). Asimismo, corresponde al Estado garantizar que las víctimas elijan a representantes en estos espacios de decisión y seguimiento a la Ley, el acceso a información y el diseño de estrategias para la adecuada participación. La misma Ley en el Artículo 193 ordena la conformación de las Mesas de Participación de Víctimas en tres niveles: municipal, departamental y nacional y "propiciando la participación efectiva de mujeres, niños, niñas $\mathrm{y}$ adolescentes, adultos mayores víctimas, a fin de reflejar sus agendas" (República de Colombia, 2011, Artículo 193).

En procura de llevar a término lo estipulado por el Gobierno Nacional, mediante la Resolución 0388 de 10 de mayo de 2013, se crea el Protocolo de Participación Efectiva de las Víctimas del Conflicto Armado, el cual establece las definiciones y los términos en los que se debe dar tal participación, siempre guiados por los siguientes principios: equidad de géneros, igualdad, autonomía, eficacia, concertación, primacía del interés general, promoción de la participación de las víctimas, enfoque diferencial, enfoque por hecho victimizante, articulación institucional, complementariedad, subsidiariedad y corresponsabilidad. La Resolución establece como espacios de participación efectiva las Mesas de Participación de las Víctimas, según lo señalado en el Artículo 264 del Decreto 4800 de 2011 y los define como:

[...] los espacios de trabajo temático y de participación efectiva de las víctimas, de orden municipal, distrital, departamental y nacional, elegidos y designados por las mismas víctimas y sus organizaciones y destinados para la discusión, interlocución, retroalimentación, capacitación y seguimiento de las disposiciones contenidas en la Ley 1448 de 2011, sus decretos reglamentarios, la jurisprudencia y demás normas complementarias (Unidad para la Atención y Reparación Integral a las Víctimas, 2013, p. 5).

La indagación hecha permite identificar que las posibilidades reales del ejercicio ciudadano en las víctimas del conflicto armado en el país son limitadas, frágiles y escasas. Los esfuerzos de las mismas víctimas, de las organizaciones de derechos humanos que han trabajado durante años por el restablecimiento de sus derechos y todo el entramado de participación compuesto por las mesas de participación de la población desplazada, hizo posible que la Ley 1448 de 2011 estableciera como un imperativo la participación de la población víctima del conflicto para la definición e implementación de políticas públicas enfocadas al restablecimiento de sus derechos. En consecuencia, se reglamentó la participación de las víctimas, se crearon protocolos, se adecuó la institucionalidad central y se establecieron las Mesas de Participación como el espacio por excelencia para que las víctimas estén presentes en las decisiones que las implican.

A la fecha de hoy, un gran número de municipios y departamentos del país cuenta con Mesas de Participación de Víctimas, así como está conformada la Mesa Nacional de Víctimas del Conflicto Armado colombiano. No obstante, los avances, la puesta en marcha de estos andamiajes presenta inconvenientes que cuestionan el ejercicio real de ciudadanía de las víctimas del conflicto armado (Comisión de Seguimiento y Monitoreo a la Implementación de la Ley 1448 de 2011, 2018, p. 240). A continuación, se destacan algunos de los mayores obstáculos a los ejercicios participativos que impiden el cumplimiento del objetivo final de la estructura creada: la participación de las víctimas en la definición e implementación de política pública.

Dentro de las variables que dificultan la participación de las víctimas se cuentan asuntos de orden práctico de la cotidianidad, así como aspectos estructurales que atañen a diversos factores. Se subraya la difícil labor de ser un líder o lideresa representante de la comunidad de víctimas y así mismo luchar día a día por la consecución de los mínimos básicos de subsistencia para sí mismo y para la familia. La situación actual de los líderes sociales en Colombia es crítica, la amenaza está al acecho y el temor intimida sus acciones reivindicatorias de derechos. "El Instituto Nacional de Medicina Legal cifró en 317 los líderes sociales asesinados en Colombia entre el 1 de enero de 2018 y el 30 de abril de 2019" (El Espectador, 2019).

Por otra parte, y en este mismo ámbito de lo práctico, se cuenta la precaria capacidad de articulación entre las entidades del orden nacional y las instancias locales y regionales, encaminadas al mismo objetivo. En este sentido, ha sido frecuente encontrar que autoridades territoriales desconocen su obligación de responder a las propuestas, observaciones y planteamientos que presentan las 
mesas de víctimas y hacen caso omiso a su verdadero rol dentro de los espacios de coordinación de acciones. A propósito de esto, la Comisión de Seguimiento y Monitoreo a la Implementación de la Ley 1448 de 2011 (2018) describe en la Medición de Capacidad (p. 246) la baja respuesta de las administraciones regionales de los departamentos seleccionados (Antioquia, Norte de Santander, Cauca, Nariño y Casanare) a las propuestas presentadas por las mesas departamentales al Plan de Acción Territorial (PAT). De acuerdo con el informe, todas las mesas de participación construyeron propuestas para ser tenidas en cuenta dentro de la construcción del PAT 2016; sin embargo, sólo las gobernaciones del Cauca y Nariño respondieron a las propuestas de la Mesa departamental. Los demás departamentos no dieron respuesta, lo cual no implica que sus propuestas no hayan sido incluidas dentro del PAT, pero “...los representantes de víctimas no tienen certeza de sus iniciativas, ni de los criterios técnicos y presupuestales con los cuales la entidad territorial tomó la decisión de inclusión o exclusión, limitando así la posibilidad de una participación informada” (p. 246).

Vale destacar en este ámbito los postulados de Martín Berrío (2013) en referencia a que uno de los principales problemas en el diseño de los procesos de participación estipulados por la Ley 1448 fue el desajuste en los tiempos entre el montaje del sistema de participación, que requirió por lo menos un año para que medianamente funcionara bien y fuese coordinado en los distintos niveles local, regional y nacional; y el tiempo que la Ley ordenaba que se adoptaran las políticas más importantes y claves, así como los decretos reglamentarios, lo cual se exigía para un tiempo menor al necesario para el montaje de las Mesas de participación. Por ende, buena parte de los diseños y políticas se hicieron sin la participación de las víctimas que preveía la Ley 1448. Martín Berrío (2013) argumenta que la participación de las víctimas se convierte en un remedo y contentillo para aquellos que cuestionan, pues a pesar de que las normas prevén que las entidades gubernamentales respondan las sugerencias o comentarios de las víctimas y sus representantes, el mecanismo de participación en conjunto está orientado a la recolección de propuestas que generalmente son archivadas.

Ahora bien, el hecho que existan los espacios para la participación no es suficiente para que esta se dé y se haga en condiciones reales, es decir, que permitan la incidencia de las víctimas en la definición e implementación de la política pública. Por ello, aunque ha sido real este espacio de participación, también es cierto que no logra aún la incidencia que se aspiraba.

Se requiere entonces acudir a otro elemento sustancial en esta reflexión que es la del sujeto ciudadano, quien ha sufrido una afectación directa o indirecta a su rol que, en palabras de Fuentes y Atehortúa, ha disminuido su ejercicio ciudadano:

Las vulneraciones de derechos que sufren las víctimas se han definido como ataques directos contra su ciudadanía, siendo este un punto central para lograr la reparación de las víctimas. De ahí que uno de los objetivos de la justicia transicional sea fortalecer el restablecimiento de la ciudadanía de las víctimas (Fuentes y Aterhortúa, 2016, p. 67).

Por tal razón, manifiestan las autoras, una de las formas de potenciar la democracia, así como el restablecimiento de las víctimas, es propiciar su participación en el diseño y desarrollo de políticas públicas tendientes a garantizar sus derechos. No obstante, plantean Fuentes y Atehortúa (2016) que la participación está mediada por la calidad de los sujetos que participan, lo que implicaría personas con información y capacidad suficiente para tomar decisiones pertinentes en relación con la autodeterminación de sus vidas. Sin embargo, las víctimas llegan a estos espacios con el supuesto de que su capacidad y posibilidad de actuar como ciudadanos ha sufrido menguas, lo cual repercute en la manera como participan.

Por otra parte, es preciso traer a la reflexión que el concepto de víctima expuesto en la Ley 1448 de 2011 limita el ejercicio ciudadano de las mismas, toda vez que el concepto no involucra a todas las víctimas que ha generado el conflicto actual, dado que solo son beneficiarios de los derechos de ley aquellas que se han registrado. Sumado a lo dicho, los espacios de participación se restringen a las víctimas inscritas en el Registro Único de Víctimas, tal como lo estipula el Artículo 16 del Protocolo que versa sobre los requisitos para ser miembros en las Mesas de Participación de Víctimas en su numeral A: "Estar inscrito en el Registro Único de Víctimas (RUV)” (Gaviria, 2013), con lo cual, aquellas que no están en el Registro no hacen parte de ello.

Aunado a lo dicho, el ejercicio ciudadano en Colombia, en particular de las víctimas del conflicto armado, es restringido y manipulado por múltiples actores a través del clientelismo. Su práctica, casi 
institucionalización y su incorporación a la vida social del país es uno de los peores males de la democracia colombiana y así mismo una de las mayores afrentas a la posibilidad real de ejercer estatus de ciudadanía. El clientelismo está en contravía frente al Estado de derecho, toda vez que su práctica va en detrimento de los principios de racionalidad y universalidad establecidos en las leyes, pues a mayor clientelismo en las relaciones de poder, también mayor debilidad institucional:

Cuando la burocracia y las decisiones estatales no obedecen a principios de racionalidad $\mathrm{y}$ universalidad previamente establecidos en las leyes, sino al intercambio de favores y de negocios entre políticos locales y nacionales o regionales, se habla de un Estado pre-moderno; un Estado en donde prevalece el clientelismo político y no la ley (García y Revelo, 2010, p. 23).

Así mismo, el clientelismo, sumado a la poca apropiación por parte de la ciudadanía de las actividades politicas, se ha acentuado con el fenómeno del narcotráfico y la violencia, desembocando en la deslegitimación del Estado de derecho y de los mecanismos de participación.

En este orden de ideas, el ejercicio real de ciudadanía de las víctimas del conflicto armado colombiano, es una constatación de la debilidad del sujeto ciudadano mismo que ha participado en la configuración del país actual y que, con un escaso ejercicio participativo, agudiza a la construcción de una democracia débil y más formal que real. Todo ello convoca a la reflexión de una temática que es escasa en su abordaje, en orden a identificar sus diversos componentes y a fortalecer la vivencia real de ejercicios participativos en un país en dinámica de posacuerdo.

\section{De-fragmentar la noción de victima: equidad de género}

La tarea de pensar el posacuerdo llama a una labor más compleja aún: cambiar las estructuras opresivas que han posibilitado la ocurrencia de la violencia. Así, en esta tercera parte del artículo, nuestro objetivo es abordar los limitantes del concepto de víctima desde una perspectiva de género.

En el marco de un conflicto armado interno como es el caso de Colombia, la equidad de género debe primero comprenderse por los impactos diferenciados vividos por las mujeres, los hombres y las poblaciones con géneros diversos (Fisas et al., 2016, p. 26). De este modo, el documento CONPES 3784 del año 2013 reconoce que las "mujeres se encuentran en situaciones de vulnerabilidad y cuyos efectos demuestran el impacto desproporcionado que tiene el conflicto sobre sus vidas" (Departamento Nacional de Planeación, 2013, p. 21) y, por tanto, se requiere una respuesta institucional clara al respecto. En el marco de la Ley 1448, los grupos de mujeres y los colectivos LGBTI fueron claves en las acciones políticas que condujeron a la adopción de ciertos postulados diferenciales en dicha ley, ya que su labor consistió en visibilizar la violencia que ha sido continua en las últimas décadas (Centro Nacional de Memoria Histórica, 2015, p.77). Así, en la Ley 1448, se propone una visión de los enfoques diferenciales en el Artículo 13, estipulando que:

Para el efecto, en la ejecución y adopción por parte del Gobierno Nacional de políticas de asistencia y reparación en desarrollo de la presente ley, deberán adoptarse criterios diferenciales que respondan a las particularidades y grado de vulnerabilidad de cada uno de estos grupos poblacionales (República de Colombia, 2011).

De esto modo, se puede afirmar que, a pesar de los limitantes en la implementación, la Ley 1448 de 2011 ha presentado unos avances fundamentales en la reivindicación de los derechos humanos de poblaciones diversas. La incorporación del enfoque diferencial es, en efecto, uno de los puntos fuertes del instrumento jurídico que ha pensado la condición de víctima en el marco del conflicto armado colombiano. Esto ha brindado a diversos grupos la posibilidad de dignificar sus luchas y tener herramientas jurídicas para avanzar en ellas. Sin embargo, en esta sección, argumentamos que la noción de víctima, tal como se entiende y se aplica a partir del enfoque diferencial, está fragmentada y dificulta la puesta en práctica de dicho enfoque. De este modo, primero consideramos cómo entendemos el género en esta investigación y, segundo, ofrecemos unas pistas de reflexión sobre la posible apertura del concepto de víctima al enfoque interseccional.

\section{Género: una critica definicional}

Las definiciones en torno al concepto de género son multifacéticas y complejas, implicando también variantes culturales y geográficas importantes. En 
esta investigación, para comprender el concepto de género, se toma como punto de partida los aportes teóricos de Judith Butler ${ }^{1}$ sobre la performatividad del género $(1988 ; 1990)$ y los postulados de las feministas decoloniales sobre la interseccionalidad de las opresiones (Espinosa-Miñoso, 2014). De esta manera, el género ya no es concebido como las diferencias biológicas entre hombres y mujeres, sino que se comprende como "una identidad instituida por una repetición estilizada de actos" (Butler, 1998, p. 297). Se considera que el género no es binario, sino que se crea la ilusión del género como identidad corpórea: las normas sociales llegan a tener un impacto sobre la constitución del sujeto que se identifica con un género masculino o femenino, provocando así, la discriminación de todos los cuerpos que no responden a estas normas establecidas en la matriz heteronormativa (Butler, 1990).

Además de esta crítica a la heteronormatividad propuesta por Butler, esta investigación analiza la categoría de género desde una mirada propuesta por las feministas decoloniales, es decir, desde una postura no hegemónica que resalta la necesidad de develar las múltiples formas de opresión y vulneración vividas por las víctimas del conflicto armado en la óptica de no revictimizarlas, pero siendo conscientes de sus diversas afectaciones. Para avanzar en la equidad real y efectiva, se necesita abordar el concepto de género desde la interseccionalidad de las opresiones (Crenshaw, 1991; Maj, 2013), es decir, considerando que no solamente un factor o una identidad definen a las personas afectadas, sino que varios enfoques diferenciales se cruzan y tejen en el hecho victimizante y en la reparación.

En este sentido, esta investigación adoptó una comprensión del género como una "construcción social intersubjectiva" que debe ser contextualizada (Sjobeg y Gentry, 2007, p.5). Además, se entiende que no es estática y que se cruza con otras (y variadas) modalidades de subjetivación. Por tanto, la equidad que se busca debe tener en cuenta, en la materialización del concepto de víctima, las múltiples vulneraciones vividas por género, raza y clase e interpelar mecanismos diferenciales de atención y reparación a víctimas.

\section{Más allá de los enfoques diferenciales: apuntes interseccionales}

Hasta el momento, la definición jurídica de los enfoques diferenciales y las dificultades prácticas de su aplicación ponen en relieve los obstáculos a la atención a víctimas mujeres, niñas y poblaciones LGBTI. Según el último informe del Centro Nacional de Memoria Histórica, en el Registro Único de Víctimas "con fecha de corte a 31 de julio de 2015, se identifican 1.795 personas con orientaciones sexuales e identidades de género no hegemónicas" (CNMH, 2015, p.42), sabiendo que estamos frente a un sub-registro de dichas poblaciones. A la fecha, el RUV (2019) identifica 29.550 eventos victimizantes relacionados con integridad sexual. Desde la implementación de la Ley 1448 de 2011, es posible afirmar que efectivamente, (1) se reconoció explícitamente los derechos particulares de las niñas y de las mujeres, así como de las personas LGBTI y (2) se mejoraron los procesos participativos de dichos colectivos ya que las víctimas empezaron a hacer parte del movimiento social de víctimas y de las instancias de participación política de las víctimas creadas con la Ley 1448 de 2011.

Sin embargo, dicha participación política representa solamente una minoría de las víctimas como se ha planteado en el estudio de Anctil Avoine y Bolívar Durán (2014). La realidad es que la equidad de género está lejos de ser una prioridad práctica de la aplicación de la Ley 1448 de 2011 . La organización Caribe Informativo relata justamente la problemática de asesinatos de líderes en derechos humanos, entre los cuales las personas que lideran grupos LGBTI siguen siendo atacadas por grupos de extrema derecha (Caribe Informativo, 2016).

De hecho, se hace evidente que la conceptualización de la noción de género invita a comprender este concepto dentro de los límites de la cultura heteronormativa dominante $\mathrm{y}$, por tanto, no tiene en cuenta un concepto amplio y práctico de equidad. En la Ley 1448, se presenta una intención de favorecer "un proceso de reconciliación nacional sobre bases sólidas de equidad e inclusión social" (MinJusticia, 2011, s.p.), pero no se especifica claramente - más allá del rol pedagógico del CNMH - las limitaciones prácticas de su aplicabilidad. Se

1 Es de notar que la filósofa posestructuralista Judith Butler ha teorizado la performatividad de género, poniendo en relieve los problemas teóricos de pensar el género "socialmente construido" como la correlación del sexo biológico. Así, propone una crítica amplia al constructivismo, el cual no tiene en cuenta que el sexo biológico también está sujeto al mismo tiempo que produce, las normas sociales (Butler, 1988; 1990). 
busca la equidad, pero no se contemplan mecanismos $\mathrm{y}$ dispositivos para efectivamente iniciar acciones que permitan lograr su alcance real.

Así, el marco de la Ley 1448 de 201 1, en sus conceptualizaciones de los enfoques diferenciales de género, no toma en cuenta la interseccionalidad de las opresiones; es decir, el enfoque diferencial es entendido como "una manifestación de políticas de la diferencia, en el sentido en que busca ofrecer una respuesta distintiva para cada grupo poblacional específico" (Arteaga Morales, 2012, p.18). De esto modo, no se hace énfasis en las opresiones vividas por las personas, sino en una esencialización de la condición de víctima a partir de una identidad fijada (por ejemplo, el ser mujer, el ser indígena, etc.). De ahí, las y los profesionales que tratan de aplicar los enfoques diferenciales se encuentran con la necesidad de aplicar mecanismos jurídicos basados en la categorización de una vulneración. Esto tiene dos consecuencias: primero, reduce la categoría de víctimas, negando las múltiples identidades $\mathrm{y}$ afectaciones vividas $\mathrm{y}$, segundo, despolitiza la condición de víctima.

En consecuencia, para realmente hacer efectivo un concepto de víctima que sea amplio y políticamente viable, se tiene que trascender el paradigma de fragmentación de las categorías identitarias y de afectación. De este modo, se trata de superar el enfoque poblacional, el cual fragmenta los grupos, las identidades y no facilita la politización de los procesos de dignificación como lo sugiere Viveros Vigoya:

El reto no es encontrar la metáfora más adecuada para expresar las relaciones entre distintas categorías de dominación y orientar las alianzas políticas que se derivan; el reto es preservar "el principio de apertura a las diferencias como una condición y no como un límite de la interseccionalidad" (Purtschert y Meyer, 2009, p. 146). (Viveros Vigoya, 2016, p. 15)

Por tanto, uno de los resultados que arroja esta investigación es que se debe tomar en cuenta, no solamente los enfoques diferenciales - es decir, la atención diferencial según la población atendida - sino la aplicación de la intersección de las diversas opresiones y vulneraciones. La definición de los conceptos de víctimas y género deben ser re-conceptualizados a partir de los aportes de las feministas decoloniales, a saber, comprendiendo que la raza, la clase y el género tienen unas consecuencias que no se pueden evaluar de forma independiente sino interrelacionada. Por ejemplo, se debe considerar que las vivencias de una mujer, indígena y proveniente de una zona rural no pueden ser analizadas solamente desde el prisma de su género, sino que necesariamente debe considerar las violencias estructurales - la exclusión económica es una forma de violencia para poder reparar adecuadamente a las personas víctimas y evitar formas de revictimización.

\section{A manera de conclusión: ¿reto en tiempos de posacuerdo?}

La necesaria tarea de pensar acerca de la concepción de víctimas solamente es posible en su propia praxis. Una praxis desde los procesos sociales, desde las mismas organizaciones sociales que luchan por reivindicar el accionar de los derechos humanos: la defensa de la vida. En ese complejo escenario que actualmente acontece en tiempos de posacuerdo de paz en Colombia, plantear la pregunta sobre el papel de las víctimas en la historia del país exige, como bien se ha mencionado, romper con la univocidad de la concepción de víctima para dar paso a la multiplicidad y, con ello, a la apertura conceptual, más allá del estricto orden jurídico e inclusive político, para dar paso al ejercicio ciudadano y la lucha por la equidad de género en Colombia.

Por supuesto, dicho reto no desconoce los avances de la Ley 1448 de 2011: en efecto, su puesta en marcha ha permitido reconocer a las víctimas en Colombia en el orden jurídico, un importante logro de las luchas sociales y un paso significativo contra la impunidad. En ese orden de ideas, también se reconocen los avances en la construcción de memoria histórica a través del CNMH, de la Unidad de Víctimas, así como otros avances derivados de la ley en términos del registro y "cuantificación" de la población víctima del conflicto armado. Sin embargo, la posición crítica en el estudio aquí expuesto, abordó la complejidad de la noción de víctima y logró destacar la importancia de un abordaje conceptual más allá del orden jurídico para darle paso a la apertura de la concepción de víctima, expresada desde elementos filosóficos, pero también del ejercicio ciudadano y del reto de romper el enfoque diferencial en aras de la equidad de género a través de la interseccionalidad.

Pero, ¿cuál es el reto en tiempos de posacuerdo de paz? Pese al nuevo aire que pareciera 
tomar la guerra, el trazado expuesto es un llamado al reconocimiento de los sobrevivientes, más allá del marco jurídico de la Ley 1448 del 2011, para pensar su incidencia político-social. En resumidas cuentas, si el presente trabajo buscó los límites del concepto de víctima, ahora también se presenta ante nosotros y nosotras como la apertura de su conceptualización. En efecto, eso significa un gran reto que no se puede obviar en su multiplicidad, un reto que invita a nuevas posibilidades: la necesidad de re-plantear la ley con el fin de dignificar y resignificar a los ciudadanos y ciudadanas en condición de víctimas y sujetos políticos, activos y transformadores de la historia reciente del país y su futuro. En pocas palabras: las y los sobrevivientes de la guerra que re-escriben la historia de Colombia.

\section{Referencias}

Anctil Avoine, P. y Bolívar Durán, J. F. (2014). Víctimas de contaminación por armas frente a la Ley 1448 de 2011: Avances, retos y dificultades. Revista Temas, 3(8), 107-122. https://doi. org/10.15332/rt.v0i8.745

Antxustegi, E. (2010). Ciudadanía y derechos sociales. Lan Harremanak, 151-165.

Arendt, H. (1970/2006). Sobre la violencia. Madrid: Alianza Editorial.

Arendt, H. (2006) Eichmann en Jerusalén. Barcelona: Editorial Debolsillo.

Arteaga Morales, B. I. (2012). Identidades, enfoque diferencial y construcción de paz. Bogotá: Universidad de Bogotá Jorge Tadeo Lozano.

Ballesteros, B., López, W. y Pearson, A. (2008). Victimología: Aproximación Psicosocial a la Víctimas. Bogotá: Universidad Javeriana.

Bohórquez, L. (2016). La construcción de una conciencia de ciudadanía en las víctimas del desplazamiento forzado en Colombia. De la titularidad formal al ejercicio real de los derechos fundamentales (tesis doctoral). Universidad de Valencia, Valencia, España.

Butler, J. (1988). Performative Acts and Gender Constitution: An Essay in Phenomenology and Feminist Theory. Theater Journal, 40(4), pp. 519-531.

Butler, J. (1990). Gender Trouble: Feminism and the Subversion of Identity. New York: Routledge.

Butler, J. (1998). Actos performativos y constitución del género: un ensayo sobre fenomenología y teoría feminista. Debate Feminista, (18).

Caribe Informativo. (2016). Por qué están asesinando a líderes de derechos humanos en Colombia. Disponible en: http://caribeafirmativo. lgbt/2016/12/14/balance-la-situacion-dere- chos-humanos-activistas-2016/

Centro Nacional de Memoria Histórica. (2015). Aniquilar la diferencia. Lesbianas, gays, bisexuales y transgeneristas en el marco del conflicto armado colombiano. Bogotá: CNHM, UARIV, USAID y OIM.

Comisión de Seguimiento y Monitoreo a la Implementación de la Ley 1448 de 2011 "Ley de Víctimas y Restitución de Tierras”. (Agosto 17 de 2018). Disponible en: http://www.defensoria.gov.co/ public/pdf/Info17 08 17.pdf

Comisión Histórica del Conflicto y sus Víctimas. (2015). Contribución al entendimiento del Conflicto armado en Colombia. Bogotá: Ediciones Desde Abajo.

Cortina, A. (1997). Ciudadanos del mundo. Hacia una teoría de la ciudadanía. Madrid: Alianza Editorial.

Crenshaw, K. (1991). Mapping the Margins: Intersectionality, Identity Politics, and Violence against Women of Color. Stanford Law Review, 43(6), 12411299. https://doi.org/10.2307/1229039

De Gouges, O. (1791). Déclaration des droits de la femme et de la citoyenne. Disponible en : http://www. siefar.org/wp-content/uploads/2015/09/ Gouges-D\%c3\%a9claration.pdf

Departamento Nacional de Planeación. (2013). Lineamientos de política pública para la prevención de riesgos, la protección y garantía de los derechos de las mujeres víctimas del conflicto armado. (Documento Conpes 3784). Bogotá: DNP.

"En Colombia han sido asesinados 317 líderes sociales desde 2018" (15 de mayo de 2019). El ESPECTADOR. Disponible en: https://www. elespectador.com/noticias/nacional/en-colombia-han-sido-asesinados-317-lideres-sociales-desde-2018-articulo-860895

Espinosa-Miñoso, Y. (2014). Una crítica descolonial a la epistemología feminista crítica. El Cotidiano, (184). Disponible en: http://www.elcotidianoenlinea.com.mx/

Fisas, V. et al. (2016). Alerta! Informe sobre conflictos, derechos humanos y construcción de paz. Barcelona: Icaria.

Fuentes, D. y Atehortúa, C. (2016). Sobre el sujeto-víctima: configuraciones de una ciudadanía limitada. Opinión Jurídica, (29), pp. 65-77. Disponible en:http://dx.doi.org/10.22395/ojum. v15n29a3

García, M. y Revelo, J. (2010). Estado alterado. Clientelismo, mafias y debilidad institucional en Colombia. Bogotá: Ediciones Antropos.

Gaviria, P. (10 de mayo de 2013). Resolución 0388 «Por la cual se adopta el Protocolo de Participación Efectiva de las Víctimas del Conflicto Amado". 
Disponible en: http://www.unidadvictimas. gov.co/sites/default/files/documentosbiblioteca/resolucion0388de10demayode2013.pdf

Habermas, J. (1999). La inclusión del otro. Estudios de teoría política. Barcelona: Ediciones Paidós.

Han, B.-C. (2013/2016). Topología de la violencia. Barcelona: Herder.

Horrach, J. (2009). Sobre el concepto de ciudadanía: Historia y modelos. Factótum, 1-22.

Jaramillo Marín, J. (2014). Pasados y Presentes de la Violencia en Colombia. Estudio sobre las Comisiones de investigación (1958-2011). Bogotá: Universidad Pontificia Javeriana.

Kymlicka, W. (1996). Ciudadanía Multicultural. Barcelona: Paidós.

Maj, J. (2013). The Significance of Intersectionality for Feminist Political Theory. E-International Relations. Disponible en: http://www.e-ir. info/2013/11/01/the-significance-of-intersectionality-for-feminist-political-theory/

Marshall, T. y Bottomore, T. (1950). Ciudadanía y clase social. Buenos Aires: Editorial Losada.

Martín Berrío, J. (2013). Las mesas de participación de víctimas: ¿Una frustración más o un mecanismo de transformación social? Derecho Público, (31), pp. 1-33. http://dx.doi.org/10.15425/ redepub.31.2013.06

MinJusticia (2011). Decreto 4800 del 20 de diciembre de 2011. Ministerio de Justicia y del Derecho, República de Colombia. Disponible en: http://legal.legis.com.co/document/Index?obra=legcol\&document=legcol b4bcde71dOfe01d0e0430a01015101d0

Movimiento de Víctimas de Crímenes de Estado (MOVICE). Disponible en: https://movimientodevictimas.org/historia/

Naciones Unidas (1985). Declaración sobre los principios fundamentales de justicia para las víctimas de delitos y del abuso de poder adoptada por la Asamblea General en su resolución 40/34, de 29 de noviembre de 1985. Disponible en: https://www.unodc.org/pdf/compendium/compendium 2006 es part 03 02.pdf,

Nader Orfale, R. (2008). La participación ciudadana como principio de la función administrativa en el contexto de la descentralización. Derecho y Realidad, 1(12), pp. 282-286.

Pateman, C. (2010). Le contrat sexuel. Paris: La Découverte.
Primo, L. (1987/2015). La Zona Gris. En Primo Levi, La trilogía de Auschwitz (497-528). Barcelona: Ediciones Península.

República de Colombia (10 de junio de 2011). Ley de Víctimas y Restitución de Tierras. [Ley 1448 de 2011]. DO: 48.096 [Diario Oficial de la República de Colombia]. Disponible en: http:// www.imprenta.gov.co

Rawls, J. (2a edición, 2a reimpresión, 2002). Teoría de la Justicia. Cambridge, Massachusetts, Estados: The Belknap Press of Harvard University Press.

Rojas Ariza, Y. H. (2017). Cuerpo de una violencia infame. Algunas apreciaciones para una Hermenéutica de la violencia. Daimon Revista Internacional De Filosofía, pp. 747-755. https://doi. org/10.6018/daimon/273121

RUV (2019). Registro Único de Víctimas. Unidad para la atención víctimas. Disponible en: https:// www.unidadvictimas.gov.co/es/registro-unico-de-victimas-ruv/37394

Sampedro Arrubla, Julio Andrés. (1998). Escritos sobre el proceso penal desde la victimología. Bogotá: Fundación Cultural Javeriana.

Sánchez, Gonzalo y Meertens, Donny (1992). Bandoleros, gamonales y campesinos. El caso de la violencia en Colombia. Bogotá: El Ancora editores.

Schmitt Carl (2014). El concepto de lo político. Madrid: Alianza editorial.

Sojberg, L. y Gentry, C.E. (2007). Monster, Whores: Women's Violence In Global Politics. New York: Zed Books.

Unidad para la Atención y Reparación Integral a Víctimas (2013). Resolución No 388 por la cual se adopta el Protocolo de Participación efectiva de las víctimas del conflicto armado. Disponible en: https://www.unidadvictimas.gov.co/sites/default/files/documentosbiblioteca/resolucion0388de10demayode2013.pdf

Viveros Vigoya, M. (2016). La interseccionalidad: una aproximación situada a la dominación. Debate Feminista, 52, pp. 1-17. https://doi.org/10.1016/j.df.2016.09.005

Wollstonecraft, M. (1996). A Vindication of the Rights of Woman. Mineola, N.Y: Dover Publications. 